\title{
Induction of apoptosis in human tumor cell lines by platelets
}

\author{
Morteza Yaftian ${ }^{1}$, Fatemeh Yari ${ }^{*}$, Mehran Ghasemzadeh $^{1}$
}

1. Blood Transfusion Research Center, High Institute for Research and Education in Transfusion Medicine, Tehran, Iran

*Corresponding author:Tel: +98 2182052238 Fax: +98 2188601555

Address: IBTO bldg, Hemmat. Exp.Way. Next to the Milad Tower, Tehran, Iran, P.O. Box: 14665-1157.

E-mail: f.yari@ibto.ir

Received; 2016/05/28 revised; 2016/06/19 accepted; 2016/07/1

\section{Abstract}

Introduction: It has been reported that platelets can eradicate tumor cells in vitro, although the mechanism of this effect has not been determined. The effect of platelets on the induction of apoptosis in tumor cells is largely unknown.

Materials and methods: To investigate this effect, two human hematologic cell lines, K562 and Daudi, were independently faced with unstimulated and thrombin-activated platelets. After the elapsed co-culture time, the levels of caspase-3 and CD95 were evaluated as a sign of cell death and apoptosis. In addition, immortalized cells were evaluated using trypan blue, 7-AAD and WST-1 methods.

Results: CD95 and caspase-3 levels were significantly increased in both cell lines compared with the control cells $(\mathrm{P}<0.05)$. Beside, considerably lower number of living cells were shown by trypan blue, 7-AAD and WST-1 in the treatment groups compared with the control group $(\mathrm{P}<0.05)$.

Conclusion: This study demonstrated the role of apoptosis in tumor inhibition and implied the ability of platelets to induce apoptosis in tumor cell lines.

Keywords: Apoptosis, Platelet, K562, Daudi, CD95

\section{Introduction}

Platelets are blood cells that play the key role in hemostasis (1). They contain a large number of biologically active proteins in the cytoplasmic granules containing alpha and dense granules, primary lysosomes and peroxisomes (2). Platelets also have several immunologically important cytokines and chemokines that are released at the time of activation $(3,4)$. Alpha granules contain a number of important growth factors, including vascular endothelial growth factor (VEGF), platelet-derived growth factor (PDGF), epidermal growth factor (EGF) and transforming growth factor beta (TGF $\beta$ ) that are effective in improving wounds and angiogenesis (5) Plateletderived VEGF not only facilitate the angiogenesis but also increase vascular permeability and the further spread of tumor cells (6). Beside, in addition to the effective factors of angiogenesis, platelets contain antiangiogenic factors such as PF4, TSP-1 and endostatin that can limit the growth and survival of cancer cells (7). This could reveal different roles of platelet secretory factors in pathophysiological process in the body. The anti-metastatic factor; PF4 can be as an available candidate in cancer therapy (8). Further investigations have revealed that the majority of tumor cells or the primary tumor tissues are able to produce soluble factors such as ADP and thrombin that could cause platelet activation as well as platelet or platelet-tumor aggregations (910). Activated platelets and microparticles released from platelets included the functional adhesion receptors of P-selectin and CD40L $(11,12)$. At the time of 
activation, platelets release two types of vesicles containing platelet microparticles and exosomes. Under the physiological conditions, these membrane vesicles are responsible for transmitting signals of platelets to other cells. Platelet-derived microparticles sprout from the membrane of activated platelets and have the membrane molecules of platelets such as CD40L that can react with cells containing CD40 receptor (13). The role of platelets in immune and inflammatory responses and defense against pathogens and malignancies is primarily occurring through several molecules, including TLR1, MHC-1, CD40 and CD40L (14). Platelets have different factors of cell growth induction or cell growth inhibition. After the co-culture of platelets with the neoplasm cells, platelets impose the cell growth inhibition effects using different mechanisms by cytotoxic effects $(15,16)$ or cell cycle preventing (17). Because of the lack of information in the field of apoptosis induction of platelets on tumor cells, we studied this issue using treatment of two cell lines with platelets or thrombin-activated platelets.

\section{Materials and methods}

Preparation of platelets: Five single donor platelet concentrate bags (JMS Singapore Plte Ltd. contained CPDA-1 solution) were prepared from Iranian Blood Transfusion Organization (IBTO). Informed consent was obtained from the blood candidates by (IBTO). Platelets were centrifuged at $300 \mathrm{~g}$ for $5 \mathrm{~min}$ to remove red blood cells (RBCs) and white blood cells (WBCs). The supernatant was centrifuged at $1200 \mathrm{~g}$ for $10 \mathrm{~min}$ to sediment platelets. Platelets were counted by an automated hematology analyzer (Sysmex K-1000, Kobe, Japan).Additionally; platelets were activated in the presence of thrombin $(3 \mathrm{U} / \mathrm{ml})$ at room temperature.

The cell lines: Two tumor cell lines were used in the present study, K562 (human chronic myelogenous leukemia cell line) and Daudi (human B Lymphoblast cell line) were provided by (NCBI) national cell bank of Iran, Pasteur Institute (Tehran, Iran).

The co-culture of platelets and cell lines: Unstimulated and thrombin-activated platelets $\left(5 \times 10^{7}\right.$ cells $)$, were independently introduced into the culture medium included K562/ Daudi $\left(1 \times 10^{5}\right.$ cells $)$ in the wells of a cell culture plate. The co-culture medium consisted of RPMI 1640 supplemented with $10 \%$ FBS, $1 \%$ penicillin and streptomycin (GIBCO, USA), prepared from a stock solution of $100 \mathrm{X}$ concentration of $10,000 \mathrm{IU} / \mathrm{mL}$ penicillin and $10,000 \mu \mathrm{g} / \mathrm{mL}$ of streptomycin and 1\% L-glutamine (200 $\mathrm{mM})$. The culture plates were incubated at $37^{\circ} \mathrm{C}$ for 48 hours in a humidified incubator with 5\% $\mathrm{CO} 2$ atmosphere. It was worthy of note that all co-cultures were performed in duplicate in the presence of appropriate controls. Controls of this study consisted of K562 or Daudi cells without any treatment.

7-AAD viability staining: 7Aminoactinomycin D (7-AAD) is a fluorescent intercalator that undergoes a spectral shift upon association with DNA. After the co-culture time, cells in each well were harvested and centrifuged at $400 \mathrm{~g}$ for $5 \mathrm{~min}$ to remove platelets. Deposited cells were washed once with assay buffer (Cayman 7-AAD assay kit, USA), resuspended in the staining solution of the kit and incubated at room temperature for $15 \mathrm{~min}$ at dark. Cells were centrifuged at $400 \mathrm{~g}$ for $5 \mathrm{~min}$ and suspended in assay buffer for analysis with flow cytometry technique.

CD95 expression levels: The expression of CD95 was studied on K562 and Daudi cells after the co-culture time by flow cytometry technique. In a one-step method, $2 \mu$ of FITC-conjugated mouse anti-CD95 antibody (eBioscience, USA) was added to the tubes each included $10^{5}$ cells in $100 \mu \mathrm{L}$. The tubes were left for 40 min at $4^{\circ} \mathrm{C}$ before analysis by flow cytometry . 
Active caspase- 3 concentration: The experiment was based on the measurement of P17 subunit of active caspase-3 inside the human cells using ELISA method (Abcam, UK). Forthy-eight hours after the co-culture, K562 and Daudi cells were lysed by the extraction buffer included in the kit after the addition of the protease inhibitor (1 $\mathrm{mM}$ PMSF).The extracted protein solutions were stored at $-80^{\circ} \mathrm{C}$. ELISA method was done as the manufacturer's instructions.

WST-1 cell proliferation and viability assay: WST-1 is a method to measure the cell proliferation. Expansion in the number of viable cells results in an increase in the activity of the mitochondrial dehydrogenases, which in turn leads to increase in the amount of formazan dye formed. After the co-culture time, cells were centrifuged at $400 \mathrm{~g}$ to remove platelets. Afterwards, $10 \mu \mathrm{L}$ of WST-1 reagent (Cayman cell proliferation assay kit, USA) was added to each well containing $100 \mu \mathrm{L}$ of cells in a 96 well plate. Subsequently, the plate was incubated for 4 hours at $37^{\circ} \mathrm{C}$. The absorbance of wells was measured with a microplate absorbance reader at the wavelength of $450 \mathrm{~nm}$.

Trypan blue exclusion test of cell viability: Trypan blue provides the possibility for detection of live and dead cells, microscopically. After the end of coculture time, the number of viable and dead cells was enumerated for the cells of each well by trypan blue. Finally, the percent of dead cells was calculated.

\section{Statistical analysis}

The non-parametric; Wilcoxon method with SPSS 16.0 software was used to compare the results of this experiment. The $\mathrm{P}<0.05$ was considered statistically significant.

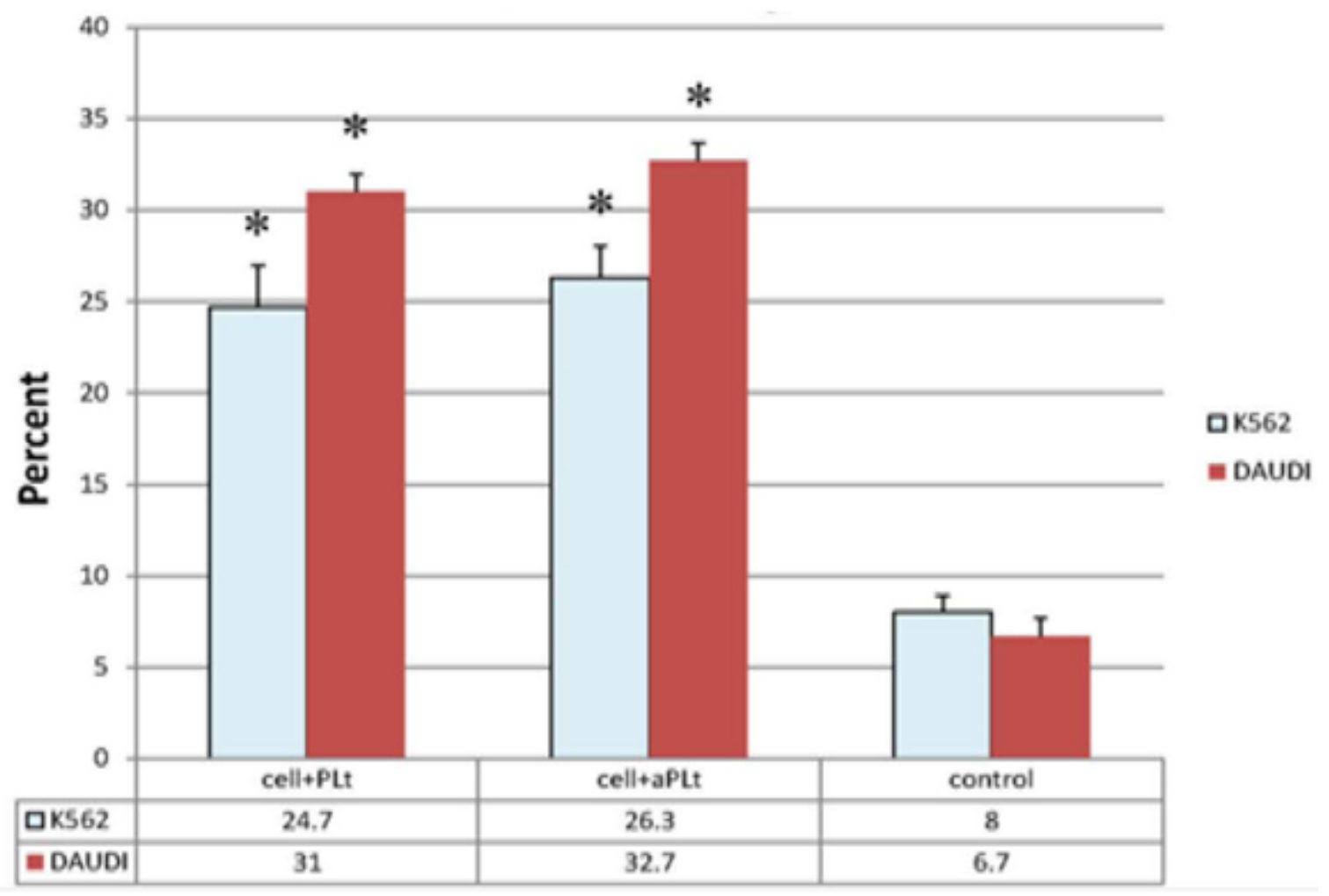

Figure 1. K562 and Daudi cell lines were treated with platelets (plt) or thrombin-activated platelets (aplt), in the 24-well culture plates. Dead cells were labeled with 7-AAD dye and measured by flow cytometry technique. Data were presented as the mean $\pm \mathrm{SD}$ of five independent experiments. * Indicates $\mathrm{P}<0.05$. 


\section{Results}

7-AAD viability staining results: The percent of 7-AAD-stained cells was measured by flow cytometry technique (Figure 1) and showed significantly greater amounts in the two treatment groups than control group $(\mathrm{P}<0.05)$.

CD95 expression: CD95 (FAS) expression was analyzed on K562 and Daudi cells after 48 hours of co-culture using the flow cytometry technique. Significantly higher expression of CD95 was detected in the treatment groups compared with the untreated control group $(\mathrm{P}<0.05)$ (Figure 2).
Active caspase-3 concentration: The concentration of human active caspase- 3 was significantly increased in the extracts of K562 and Daudi cells after the coculture time compared with the control group $(\mathrm{P}<0.05)$ (Figure 3$)$.

Trypan blue and WST-1 results: Trypan blue (Figure 4) and WST-1 (Figure 5) showed significantly increased number of dead cells in the cell lines after the treatments in compare with the untreated control cells. The differences between the treatment cases with control was significant $(\mathrm{P}<0.05)$.

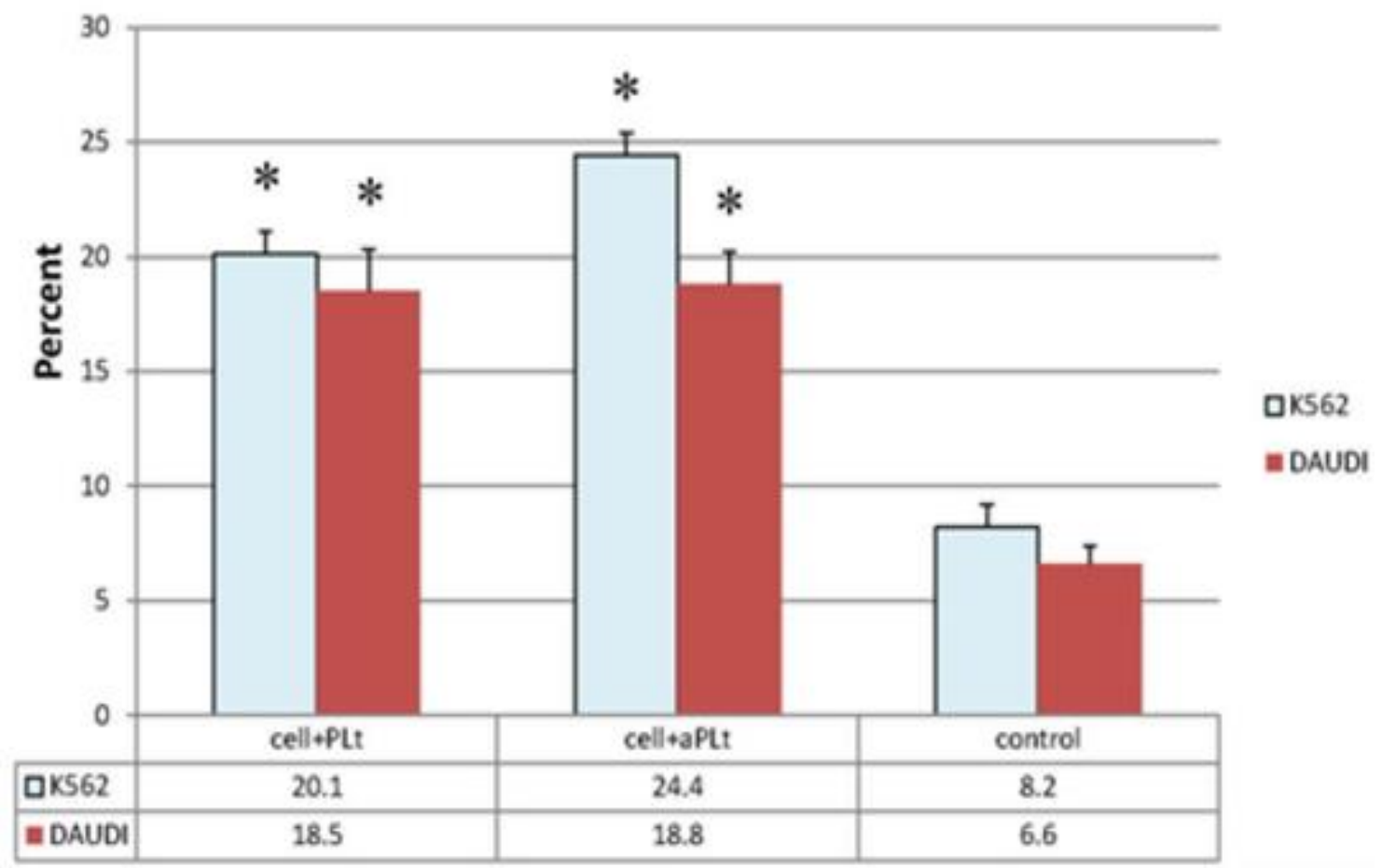

Figure 2. K562 and Daudi cell lines were treated with platelets (plt) or thrombin-activated platelets (aplt), in the 24-well culture plates. Higher expression of CD95 was shown in the treatment groups compared with the control group. Data were presented as the mean $\pm \mathrm{SD}$ of five independent experiments. * Indicates $\mathrm{P}<0.05$. 


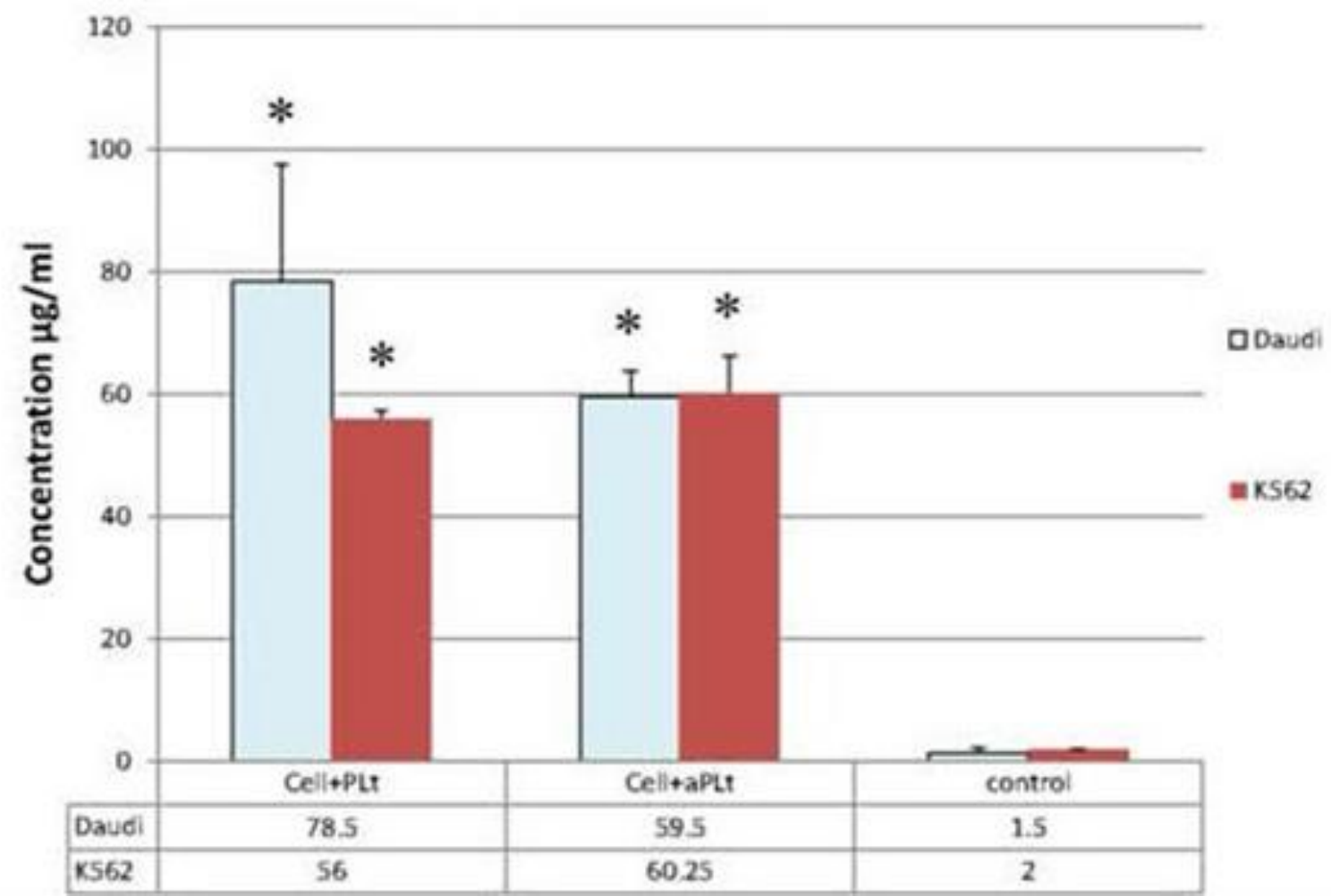

Figure 3. Active caspase-3 levels in K562 and Daudi cell lines after treatment with platelets (plt) or thrombinactivated platelets (aplt). Higher concentrations of caspase-3 were shown because of the platelets (plt) or thrombin-activated platelets (aplt). Data were presented as the mean \pm SD of five independent experiments. *Indicates $\mathrm{P}<0.05$.

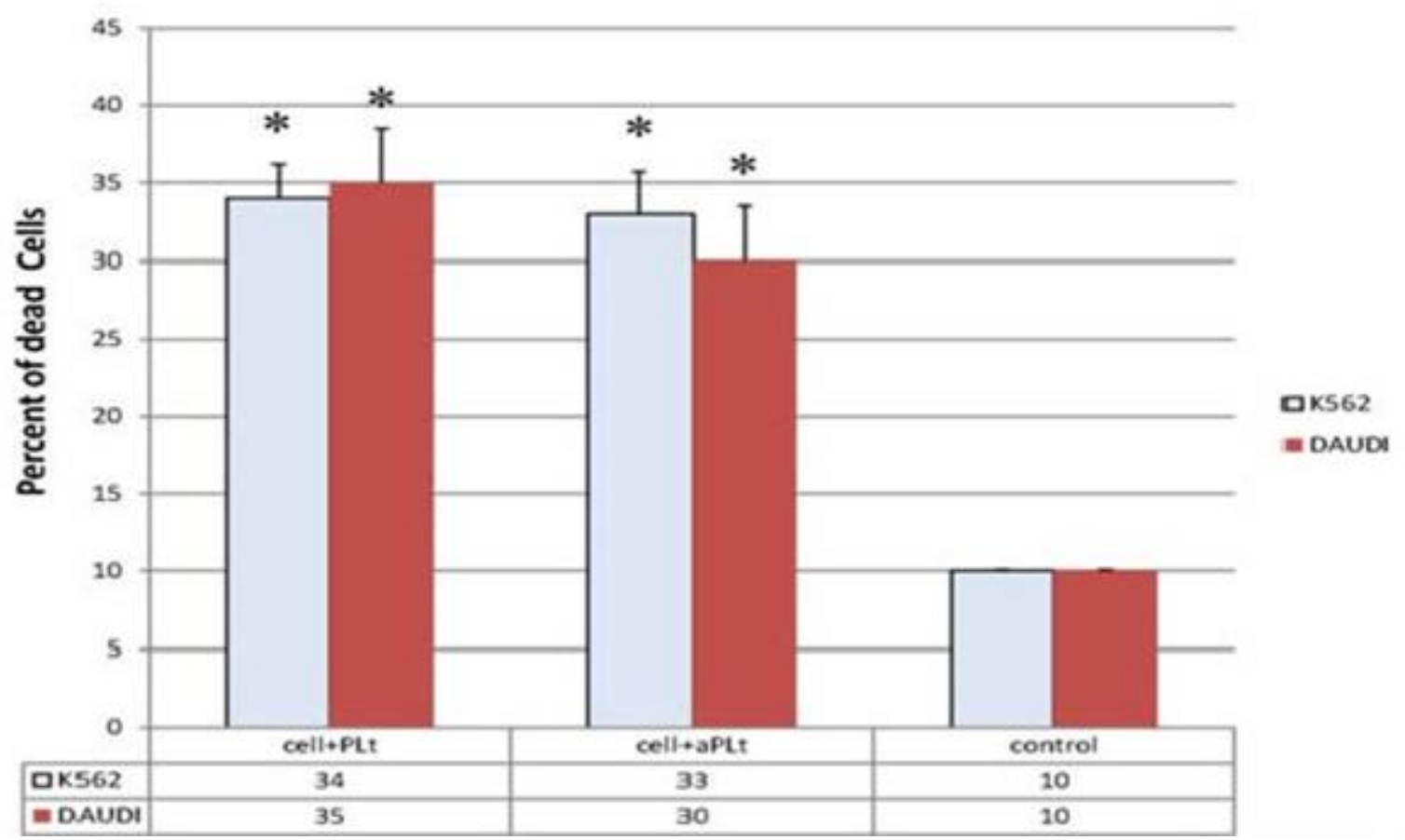

Figure 4. Trypan blue results. Plasma membrane of non-viable cells was permeable to trypan blue whereas live cells remained unstained. The number of viable and dead cells was counted microscopically after treatment with platelets (plt) or thrombin-activated platelets (aplt). The percent of dead cells was calculated. Data were presented as the mean $\pm \mathrm{SD}$ of five independent experiments. ${ }^{*}$ Indicates $\mathrm{P}<0.05$. 


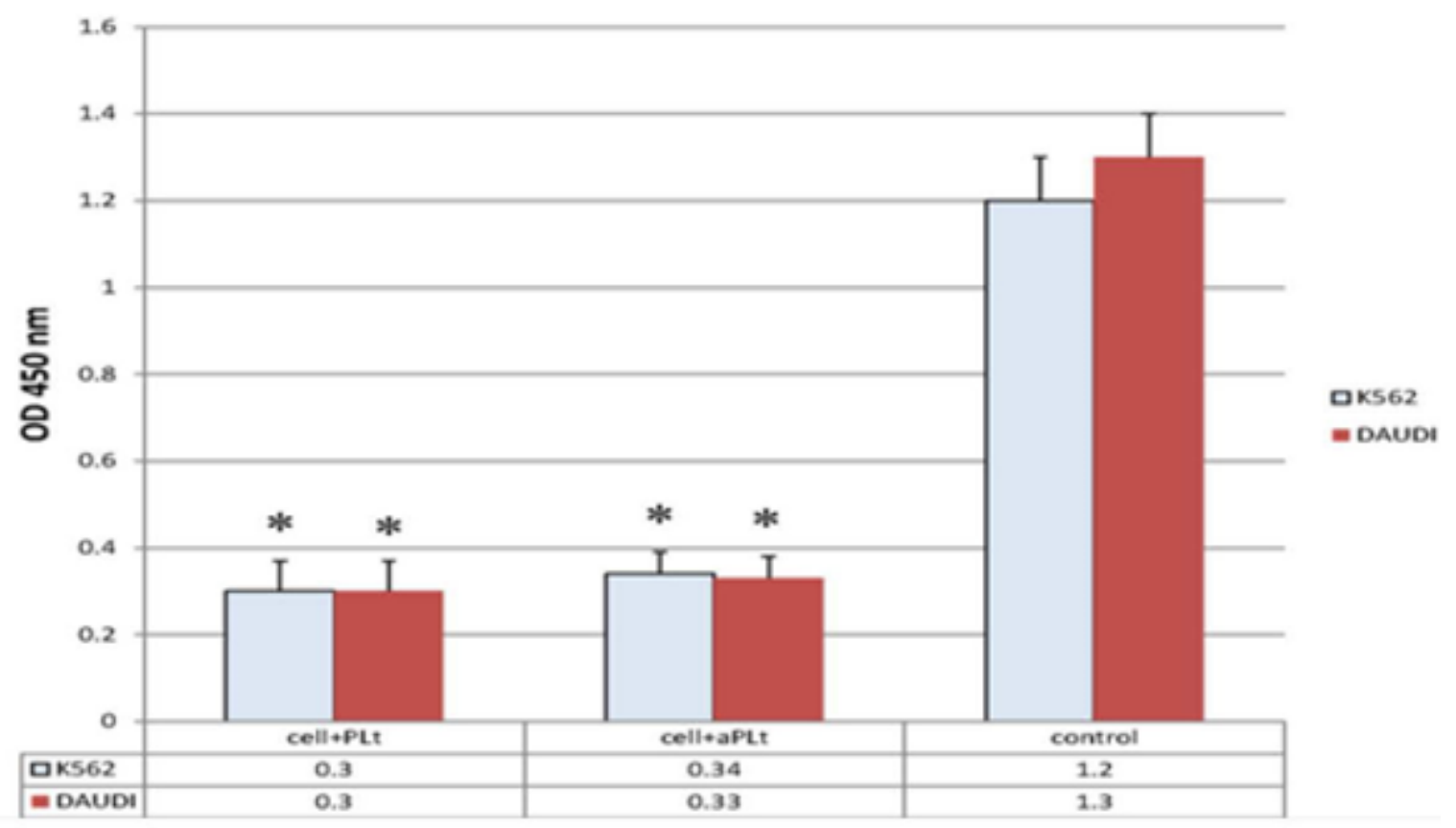

Figure 5. WST-1 results. Enzymatic cleavage of the tetrazolium salt (WST-1) to formazan by cellular mitochondrial dehydrogenases was measured with absorbance reading at the wavelength of $450 \mathrm{~nm}$. Exposure with plts or thrombin-activated platelets (aplt) caused lower viability and metabolic activity of the cell lines. Data were presented as the mean \pm SD of five independent experiments. * Indicates $\mathrm{P}<0.05$.

\section{Discussion}

Despite the role of platelets in tumor spread in the body (18), the cancer killing effects of platelets has been identified for some cell lines $(15,19)$. We studied the viability and apoptosis of cell lines after co-culture with platelets or thrombinactivated platelets. The results indicated that both platelets and thrombin-activated platelets could cause growth inhibition and apoptosis in the K562 and Daudi cells after 48 hours of co-culture.

Our study with K562 and Daudi cells were correlated with the studies of some researchers. Examples: Kawamura and coworkers showed that platelets have roles in cell growth inhibition and killing of some neoplasm cells (20). Ible and co-workers showed that the produced materials in the arachidonate metabolism pathway of platelets were toxic for some tumor cell lines (15). Bykovskaya and co-workers demonstrated that platelets isolated from the blood of oncology patients as well as healthy people can cause cytotoxic effects on several types of tumor cell lines (21).
However, the findings of this study were disagreed with that of Wang who claimed that the inhibition of tumor cell growth by platelets was mainly due to the cell cycle arrest and not apoptosis or cell death (17). We also showed that the thrombinactivated platelets and unstimulated platelets both have nearly similar influences on tumor cell lines. Correlated with us, Sagawa and co-workers reported that the thrombin-activated platelets such as unstimulated platelets have cytotoxic effects on some tumor cell lines but due to different morphological changes made in tumor cells, their effects may be carried out with different mechanisms (16).

The present study showed high expression levels of CD95 (FAS) on the studied cells after treatment with platelets or thrombinactivated platelets. This effect may be related to soluble or cell surface CD40L on platelets. It has been found that CD40CD40L ligation, up regulates Fas expression on tumor cells $(22,23)$ and enhanced FAS expression should 
predispose cells to apoptosis (24).On the contrary, Gogstad showed that the supernatant of thrombin-activated platelets had no cytotoxic effects on tumor cells although it contained various soluble materials that are secreted from activated platelets (25).

The results of this study showed similarity between the effects of platelets and thrombin-activated platelets on cancer cells. We described the apoptotic cell death effects of unstimulated platelets and thrombin-activated platelets on K562 and Daudi cells for the first time. This study implied the capability of platelets or plt-

\section{References}

1. Kosaki G. In vivo platelet production from mature megakaryocytes: does platelet release occur via proplatelets? Int J Hematol. 2005; 81(3):208-19.

2. Bentfeld ME, Bainton DF. Cytochemical localization of lysosomal enzymes in rat megakaryocytes and platelets. J Clin Invest. 1975; 56(6):1635-49.

3. Aiura K, Clark BD, Dinarello CA, Margolis NH, Kaplanski G, Burke JF, et al. Interaction with autologous platelets multiplies interleukin-1 and tumor necrosis factor production in mononuclear cells. J Infect Dis. 1997; 175(1):123-9.

4. Weyrich AS, Elstad MR, McEver RP, McIntyre TM, Moore KL, Morrissey $\mathrm{JH}$, et al. Activated platelets signal chemokine synthesis by human monocytes. J Clin Invest. 1996; 97(6):1525-34.

5. Erpenbeck L, Schön MP. Deadly allies: the fatal interplay between platelets and metastasizing cancer cells. Blood. 2010; 115(17):3427-36.

6. Dvorak HF, Detmar M, Claffey KP, Nagy JA, van de Water L, Senger DR. Vascular permeability factor/vascular endothelial growth factor: an important mediator of angiogenesis in derived components in growth inhibition of some tumor cells under the appropriate conditions. Further studies are needed to clear the effective factors of platelets in tumor growth inhibition.

\section{Acknowledgments}

This study was the result of a $\mathrm{PhD}$ thesis financially supported by Blood Transfusion Research Center, High Institute for Research and Education in Transfusion Medicine, Iranian Blood Transfusion Organization, Tehran.

malignancy and inflammation. Int Arch Allergy Immunol. 1995; 107(13):233-5.

7. Bambace NM, Holmes CE. The platelet contribution to cancer progression. J Thromb Haemost. 2011; 9(2):237-49.

8. Wang Z, Huang H. Platelet factor-4 (CXCL4/PF-4): an angiostatic chemokine for cancer therapy. Cancer Lett. 2013; 331(2):147-53.

9. Nierodzik ML, Klepfish A, Karpatkin S. Role of platelets, thrombin, integrin IIb-IIIa, fibronectin and von Willebrandfactor on tumor adhesion in vitro and metastasis in vivo. Thromb Haemost. 1995; 74(1):282-90.

10. Jennings LK. Mechanisms of platelet activation: need for new strategies to protect against platelet-mediated atherothrombosis. Thromb Haemost. 2009; 102(2); 248-57.

11. Elzey BD, Sprague DL, Ratliff TL. The emerging role of platelets in adaptive immunity. Cell Immunol. 2005; 238(1):1-9.

12. Elzey BD, Tian J, Jensen RJ, Swanson AK, Lees JR, Lentz SR, et al. Plateletmediated modulation of adaptive immunity. A communication link between innate and adaptive immune 
compartments. Immunity. 2003; 19(1):9-19.

13. Sprague DL, Elzey BD, Crist SA, Waldschmidt TJ, Jensen RJ, Ratliff TL. Platelet mediated modulation of adaptive immunity: unique delivery of CD154 signal by platelet-derived membrane vesicles. Blood. 2008; 111(10):5028-36.

14. Cognasse F, Hamzeh-Cognasse $\mathrm{H}$, Lafarge S, Chavarin $\mathrm{P}$, Cogné $\mathrm{M}$, Richard Y, et al. Human platelets can activate peripheral blood $\mathrm{B}$ cells and increase production of immunoglobulins. Exp Hematol. 2007; 35(9):1376-87.

15. Ibele GM, Kay NE, Johnson GJ, Jacob HS. Human platelets exert cytotoxic effects on tumor cells. Blood. 1985; 65(5):1252-5.

16. Sagawa T, Tominaga A, Kodama T, Okada M. Cytotoxicity of unstimulated and thrombin-activated platelets to human tumour cells. Immunology. 1993; 78(4):650-56.

17. Wang Y, Zhang H. Platelet-induced inhibition of tumor cell growth. Thromb Res. 2008; 123(2):324-30

18. Connolly GC, Phipps RP, Francis CW. Platelets and cancer-associated thrombosis. Semin Oncol. 2014; 41(3):302-10.

19. Okada M, Sagawa T, Tominaga A, Kodama T, Hitsumoto Y. Two mechanisms for platelet-mediated killing of tumour cells: one cyclooxygenase dependent and the other nitric oxide dependent. Immunology. 1996; 89(1):158-64.
20. Kawamura M, Koshihara Y. Prostaglandin D2 strongly inhibits growth of murine mastocytoma cells. Prostaglandins Leukot Med. 1983; 12(1):85-93.

21. Bykovskaya SN, Bolvacheva AV, Kiselevsky MV, Khaylenko VA, Bykovsky AF. Platelet-mediated cytotoxicity and its enhancement by platelet activating factor. Biomed Pharmacother. 1991; 45(7):279-88.

22. Afford SC, Randhawa S, Eliopoulos AG, Hubscher SG, Young LS, Adams DH. CD40 activation induces apoptosis in cultured human hepatocytes via induction of cell surface fas ligand expression and amplifies fas-mediated hepatocyte death during allograft rejection. J Exp Med. 1999; 189(2):441-6.

23. Qu X, Felder MA, Perez Horta Z, Sondel PM, Rakhmilevich AL. Antitumor effects of anti-CD40/CpG immunotherapy combined with gemcitabine or 5-fluorouracil chemotherapy in the B16 melanoma model. Int Immunopharmacol. 2013; 17(4):1141-7.

24. Garrone P, Neidhardt EM, Garcia E, Galibert L, van Kooten C, Banchereau J. Fas ligation induces apoptosis of CD40-activated human B lymphocytes. J Exp Med. 1995; 182(5):1265-73.

25. Gogstad GO, Hagen I, Korsmo R, Solum NO. Evidence for release of soluble, but not of membraneintegrated, proteins from human platelet alpha-granules. Biochim Biophys Acta. 1982; 702(1): 81-9. 